\title{
RESEÑA. APORTACIONES EN TORNO A LA MÚSICA Y LA EDUCACIÓN MUSICAL. CÓMO GENERAR EL CAMBIO A TRAVÉS DE LA REFLEXIÓN DOCENTE.
}

\author{
REVIEW. APORTACIONES EN TORNO A LA MÚSICA Y LA EDUCACIÓN \\ MUSICAL. CÓMO GENERAR EL CAMBIO A TRAVÉS DE LA REFLEXIÓN \\ DOCENTE.
}
RESENHA. APORTACIONES EN TORNO A LA MÚSICA Y LA EDUCACIÓN MUSICAL. CÓMO GENERAR EL CAMBIO A TRAVÉS DE LA REFLEXIÓN DOCENTE.

\author{
Ascensión García de las Mozas \\ Universidad de Cádiz, España \\ https://orcid.org/0000-0002-5270-6633 \\ ascension.garcia@uca.es
}

Recibido: 10/02/201 Revisado: 03/03/2021 Aceptado: 03/03/2021 Publicado: 06/03/2021

Autor: Héctor Archilla Segade (Coord.)

Editorial: Universidad de Extremadura.

APORTACIONES EN TORNO A LA MUSICA

Y LA EDUCACIÓN MUSICAL

Año: 2019

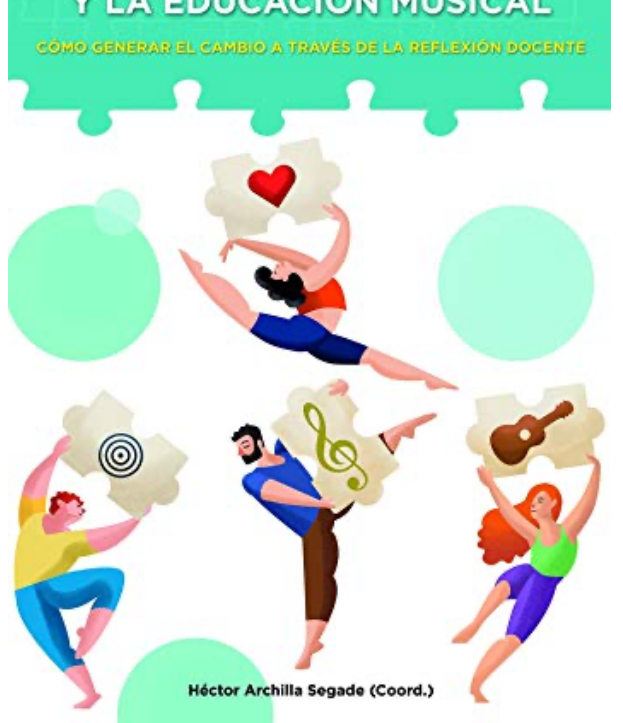

Cómo citar esta reseña: García de las Mozas, A. (2021). Reseña. Aportaciones en torno a la música y la educación musical. Cómo generar el cambio a través de la reflexión docente.. Hachetetepé. Revista científica en Educación y Comunicación, (22), 1-3. https://doi.org/10.25267/Hachetetepe.2021.i22.1302

El libro titulado Aportaciones en torno a la música y la educación musical. Cómo general el cambio a través de la reflexión docente, coordinado por Héctor Archilla Segade, maestro especialista en Educación Musical, recoge reflexiones y aportaciones, desde diferentes perspectivas, en torno a la educación musical con el objetivo de 
intercambiar ideas y continuar así transformando estas enseñanzas, mejorándolas y aumentando su calidad en las aulas del siglo XXI.

Se ha contado en dicha publicación con la colaboración de expertos relacionados con la Comunidad Autónoma de Extremadura y con la Asociación de Profesionales en Educación Musical de Extremadura (APEMEX) Bonifacio Gil.

El volumen contiene diez estudios. El primero de ellos, "Aportaciones metodológicas para la música en educación infantil y primaria", ha sido elaborado por Eunate Izaola Ibáñez y Carolina Correa González. En él se refieren a un proyecto que iniciaron ambas en 2019, llamado "Musiquino", con el que introdujeron las canciones tradicionales y populares en la educación musical infantil. Se trata de un interesante trabajo y de un material útil para todo el profesorado de música en Educación Infantil y Primaria en Extremadura.

Pilar Alcántara González realiza el segundo de los estudios que lleva por título "Musiversos". La música y la poesía son empleados como recurso didáctico para traer a las clases de Infantil y Primaria afectos, emociones, sentimientos y experiencias cercanas

El tercer trabajo, denominado "Experiencias musicales para desarrollar el talento emprendedor", lo presenta el coordinador de este libro, Héctor Archilla Segade. En él destaca que el fomento de la cultura emprendedora es una necesidad de la sociedad europea, y que se debería dar a conocer como estudiar en el aula a través del trabajo por proyectos, de manera colaborativa y dando valor a la identificación del proceso de enseñanza buscando ampliar los niveles de autonomía personal, liderazgo, invención y destrezas empresariales a través de prácticas musicales.

El siguiente trabajo titulado "In vino veritas" Brindemos por una enseñanza de calidad", de Javier Atance Ibar analiza el sistema educativo haciendo un símil con la cultura del vino. Este autor intenta revalorizar, honrar y fomentar el mundo educativo en general y al profesorado en particular. El autor nos hace descubrir que trabajar a solas es poco provechoso y que el cambio o renovación del sistema actual tiene que contar con profesores, sociedad y estado.

Los autores Sebastián Díaz Iglesias y Rosario Guerra Iglesias nos presentan su investigación titulada: "10 años de guitarra como instrumento del alumnado en educación secundaria". Nos proponen también la incorporación en las aulas de Secundaria de la guitarra española partiendo de la gran motivación que los alumnos adolescentes muestran hacia este instrumento esencial en la educación musical. Además de aportar los aspectos puramente musicales, la guitarra permite al alumno sociabilizarse, también el trabajo cooperativo, la integración, la educación en valores, acompañamiento de canciones que favorecerá la interdisciplinariedad.

Según Adolf Murillo Ribes, el proceso creativo no debe tener límites y en su trabajo titulado: "Una mirada creativa sobre las prácticas musicales: Reflexiones personales sobre un encuentro de formación para docentes de música en Badajoz", nos plantea que la creación debería romper a veces con lo establecido, con las normas.

Roberto García Gontán en su estudio "Experiencias didácticas para la integración social mediante soundpainting: composición en tiempo real", presenta un lenguaje relacionado con la creación musical. Con este método "Soundpainting" (lenguaje universal de señales para la composición en vivo en el ámbito de las artes visuales e interpretativas) busca ir más allá de la reproducción de la música, fomentando la experimentación, la improvisación, etc. 
Ángel María Horrillo Duque en su trabajo "La guitarra escolar", propone la guitarra como alternativa a los instrumentos musicales más habituales en las aulas, como por ejemplo la flauta dulce.

En "La música en Extremadura. Recursos y propuestas didácticas", los autores Sebastián Díaz Iglesias y Rosario Guerra Iglesias, presentan su obra "La música en Extremadura. Teoría y didáctica", como ejemplo de material para ser utilizado por los docentes, dando a conocer el trabajo que sobre la música en general se ha hecho y se hace en esa comunidad.

Ante las dudas que pueden plantearse a la hora de formar un Coro Escolar Infantil, Manuel de los Reyes Cabrera Díaz da unas pautas para su creación y también sobre la mejor manera de trabajar la voz con el alumnado de Infantil y Primaria.

La comunidad educativa debe felicitarse por estas reflexiones de expertos docentes que enriquecen la educación musical y son un ejemplo que puede aplicarse no solo en Extremadura, sino en el resto de las comunidades españolas.

\section{REFERENCIA BIBLIOGRÁFICA}

Archilla, H. (Coord.).(2019). Aportaciones en torno a la música y la educación musical. Cómo generar el cambio a través de la reflexión docente. Universidad de Extremadura. 